(2) Open Access Full Text Article

\title{
Intra-articular platelet-rich plasma versus hyaluronic acid in the treatment of knee osteoarthritis: a meta-analysis
}

This article was published in the following Dove Press journal:

Drug Design, Development and Therapy

\author{
Hua-feng Zhang' \\ Chen-guang Wang' \\ Hui Li' \\ Yu-ting Huang ${ }^{2}$ \\ Zhi-jun Li'
}

'Department of Orthopaedics, Tianjin Medical University General Hospital, Tianjin, People's Republic of China; ${ }^{2}$ Cancer \& Immunology Research, Children's Research Institute, Children's National Medical Center, Washington DC, USA
Correspondence: Zhi-jun Li Department of Orthopaedics, Tianjin Medical University General Hospital, No.I54 Anshan Road, Heping

District, Tianjin 300052, People's

Republic of China

Tel +86 I35 I223 3 I |4

Fax +8602260362062

Email zyyhanson@I63.com
Purpose: Platelet-rich plasma (PRP) and hyaluronic acid (HA) have been increasingly used in recent years to treat knee osteoarthritis (OA). However, whether PRP is superior to HA is controversial.

Methods: We conducted an electronic search of PubMed, Embase, ScienceDirect, and Cochrane library. The pooled data were analyzed using RevMan 5.1.

Results: Three prospective and ten randomized trials were identified. PRP injections reduced pain more effectively than HA injections in OA of the knee at 6 months (mean difference $[\mathrm{MD}]=-14.18 ; 95 \%$ confidence interval $[\mathrm{CI}]:-26.12$ to $-2.23 ; P=0.02 ; P^{2}=95 \%$ ) and 12 months (MD $=-15.25 ; 95 \% \mathrm{CI}:-22.17$ to $-8.32 ; P<0.01 ; P^{2}=81 \%$ ) of follow-up evaluated by Western Ontario and McMaster Universities Osteoarthritis Index (WOMAC) pain score, while the VAS showed no significant difference at 3 months $(\mathrm{MD}=-0.98 ; 95 \% \mathrm{CI}:-2.55$ to $0.59 ; P=0.22$; $P^{2}=90 \%$ ) and 6 months ( $\mathrm{MD}=-0.82 ; 95 \% \mathrm{CI}:-1.80$ to $0.16 ; P=0.1 ; I^{2}=83 \%$ ). Additionally, similar results were observed for the function recovery according to the WOMAC function score and EuroQol-visual analog scales.

Conclusion: The intra-articular injection of PRP was not obviously superior to HA in knee OA. Due to the limited quality and data of the evidence currently available, more high-quality randomized controlled trials are required.

Keywords: knee, osteoarthritis, hyaluronic acid, platelet-rich plasma

\section{Introduction}

Osteoarthritis (OA) is the most common joint disease with characteristics of progressive loss of joint cartilage, changes in the synovial membrane, and reduced viscosity of the synovial fluid. ${ }^{1}$ More than $30 \%$ of people over 50 years of age suffer from knee OA based on radiographic imaging. ${ }^{2}$ The need for knee arthroplasty has significantly increased, resulting in economic burdens from pain control and work performance loss with an increase in life expectancy ${ }^{3}$ and the obesity epidemic. ${ }^{4,5}$

Despite societal and health care advances, there are no medications or surgical interventions yet proven to alter the course of OA development. Topical medications are often used intra-articularly to relieve pain and increase joint functions, but they are not effective in cases of severe OA. ${ }^{6}$ Intra-articular hyaluronic acid (HA) injection is widely used for treating knee $\mathrm{OA}$, which provides treatment efficacy due to its visco-induction properties of increasing joint lubrication, as reported in many studies and meta-analysis. ${ }^{7,8}$

The promotion of growth factors in cartilage repair has been studied in vitro and in vivo ${ }^{9-12}$ to stimulate cell functions, such as proliferation and differentiation, matrix synthesis, and chondrocyte metabolism. ${ }^{13}$ Platelet-rich plasma (PRP) is an autologous 
concentration of human platelets by centrifugation of the patient's blood, ${ }^{14}$ which contains many components, including growth factors, cytokines, and many other mediators. ${ }^{13,15,16}$ In a systematic review, Kon et al concluded that published studies support the application of PRP in the treatment of tendinous, ligamentous, cartilaginous, and muscular injuries. ${ }^{17}$ Similarly, Laudy et al reported that PRP injections provide more pain relief than placebo injections in knee OA. However, they acknowledged that the level of evidence was "limited" due to the high risk of bias. ${ }^{18}$

Many studies compared PRP and HA to determine which was better and have not achieved consensus in terms of pain relief and function recovery. In a rabbit model of knee OA, Liu et al reported that PRP is better in promoting the restoration of the cartilage. ${ }^{19}$ Sanchez et al showed superior short-term results in alleviating symptoms of mild to moderate OA of the knee for PRP compared to HA in a randomized controlled trial. ${ }^{20}$ However, no difference was found between HA and PRP in the patient-reported Western Ontario and McMaster Universities Osteoarthritis Index (WOMAC) pain score at 24 or 52 weeks in the study by Cole et al. ${ }^{21}$ A meta-analysis published in 2016 showed that PRP was more effective than HA. ${ }^{22}$ However, only seven studies were included in this meta-analysis, and one was a retrospective study. ${ }^{23}$ More randomized trials were published later. Therefore, there is a need to update the comparison between PRP and HA. We aim to identify all prospective, randomized trials published to date to provide the latest insight on the efficacy of the use of PRP and HA in treating knee OA.

\section{Materials and methods}

The present study was completed according to the preferred reporting items for systematic review and meta-analyses (PRISMA) statement.

\section{Search strategy}

To identify all possible articles that meet the predefined inclusion criteria, an electronic search of PubMed (1966-September 2017), Embase (1980-September 2017), ScienceDirect (1985September 2017), and Cochrane library (1966-September 2017) was performed according to the Cochrane Collaboration guidelines. Additionally, manual searches of the reference lists of all included studies were conducted to identify trials that the electronic search may have missed. All searches were conducted based on the following terms "osteoarthritis", "knee", "hyaluronic acid or HA", and "platelet-rich plasma or PRP" with the Boolean operators "AND or". Two reviewers independently assessed the titles and abstracts of reports identified by the electronic and manual searches. Full text articles were retrieved to facilitate identification based on the abstract, when necessary. Any disagreements were resolved through discussion.

\section{Selection criteria}

Trials with the following characteristics were included: 1) patients diagnosed with knee OA; 2) comparison of HA and PLP; 3) randomized or prospective trials; and 4) full text articles available with detailed information. We excluded retrospective articles, nonrandomized studies, and articles for which we were unable to obtain the full text and relevant data for pooled analysis.

\section{Quality assessment}

The quality assessment of randomized trials was conducted using the Cochrane Collaboration "Risk of bias". Prospective studies were assessed by the index for nonrandomized studies form. Disagreements were resolved by consensus or in consultation with the senior reviewer.

\section{Data extraction}

Two authors independently extracted all the information about the study design, publication year, patient demographics, PRP and HA interventions, parameters for evaluation, adverse events, and follow-up duration for each treatment group from the included articles. We attempted to contact authors for supplementary information when the reported data were inadequate.

\section{Data analysis and statistical methods}

Because different follow-up times were used in these identified articles, we pooled and calculated data from around a similar time frame. Data from follow-up in the second or third month were merged, as were data from week 48 or 52. The meta-analysis was performed using RevMan 5.1 for Windows (Cochrane Collaboration, Oxford, UK). Risk difference and 95\% confidence intervals (CIs) were calculated for dichotomous outcomes, while the mean difference (MD) and 95\% CI were calculated for continuous outcomes. Statistical heterogeneity was assessed using a standard chi-square test and was considered significant for $P<0.05$ and $I^{2}>50 \%$. When there was significant heterogeneity, pooled data were analyzed using a random effects model. Otherwise, a fixed effects model was used for the analysis.

\section{Results}

\section{Literature search}

Figure 1 shows the process of the study selection and inclusion. A total of 124 potential studies were identified with 


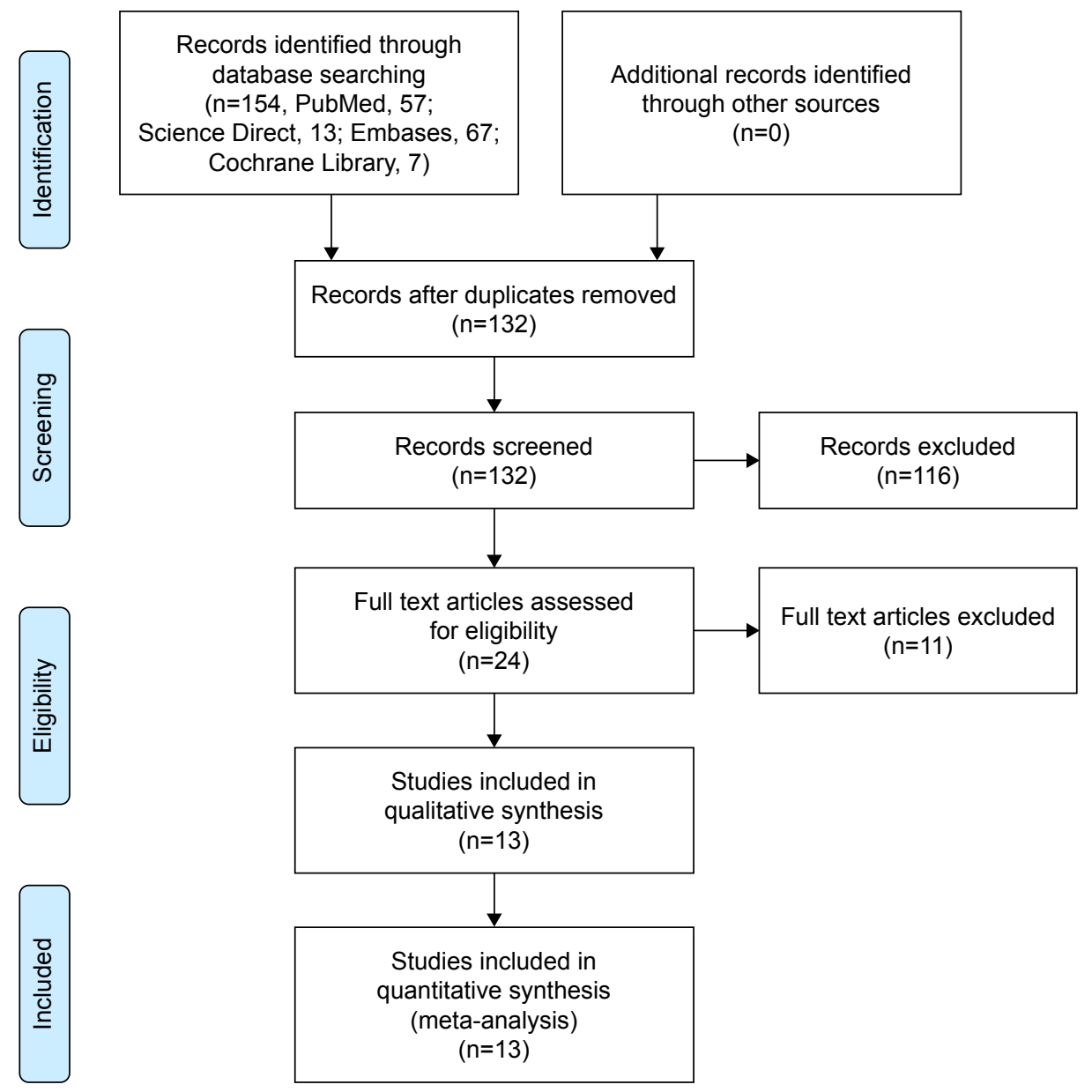

Figure I Flowchart of the study selection process.

the first search strategy. Of these, 110 studies were excluded according to the eligibility criteria. No additional studies were obtained after the manual reference review. First, we identified 14 studies that satisfied the predefined inclusion criteria. Among these studies, Filardo et al published similar results comparing PRP and HA in 2012 and 2015. We excluded the article published in 2012 after careful comparison of the two studies. Eventually, three prospective studies $^{9,24,25}$ and ten randomized trials ${ }^{20,21,26-33}$ were included in final quality assessment and data extraction.

\section{Study characteristics}

Individual patient data were available from these articles except for data for those lost to follow-up. The characteristics of the included studies are summarized in Table 1. These studies were published from 2011 to 2017 with more female patients than male patients (895 versus 625). Comparable patients were included in the PRP group (788) and HA group (736). Grade 0 (Kellgren and Lawrence classification) was chondropathy of knee without clear OA appearance on
X-ray. Early appearance was grades 1-3, while grade 4 was defined as advanced appearance. Three studies ${ }^{9,27,30}$ enrolled 72 advanced knees, while only one study ${ }^{9}$ included 62 grade 0 patients. Therefore, 1,390 participants (91.2\%) in these studies were in the early stage from grades 1 to 3 .

\section{Quality assessment}

For all randomized trials, there were no detailed descriptions on reporting bias and other biases. Performance and detection bias were not described in the studies by Cerza et al, ${ }^{26}$ Raeissadat et al, ${ }^{30}$ and Duymus et al. ${ }^{32}$ Additionally, the patients in the study by Cerza et al were consecutively randomized into groups by admission to the hospital, causing selection bias. All methodological processes are shown in Figure 2. For the other three prospective studies, the calculation of the sample size or unbiased assessment of the study endpoints could not be identified in the articles (Table 2).

\section{Outcomes of the meta-analysis}

The WOMAC was the most used tool to evaluate the effects of PRP or HA in the included studies. ${ }^{20,21,25-27,30-32}$ 
Table I Detailed information of the included studies

\begin{tabular}{|c|c|c|c|c|c|c|c|}
\hline Reference & Group & $\begin{array}{l}\text { Age } \\
\text { (years) }\end{array}$ & $\begin{array}{l}\text { Gender } \\
\text { (M/F) }\end{array}$ & $\begin{array}{l}\text { OA type } \\
\text { (C/E/A) }\end{array}$ & BMI $\left(\mathbf{k g} / \mathrm{m}^{2}\right)$ & Intervention & $\begin{array}{l}\text { Follow-up } \\
\text { (months) }\end{array}$ \\
\hline Kon et al, & PRP & $50.6 \pm 13.8$ & $30 / 20$ & C22; E20; A8 & $24.6 \pm 3.2$ & 3 times, $5 \mathrm{~mL}$, every 2 weeks & 2,6 \\
\hline \multirow[t]{2}{*}{$2011^{9}$} & HWHA & $54.9 \pm 12.6$ & $25 / 25$ & C2I; EI9; AIO & $24.8 \pm 3.5$ & $30 \mathrm{mg} / 2 \mathrm{~mL}, \mathrm{l}, 000$ to $2,900 \mathrm{kDa}$ & \\
\hline & LWHA & $53.2 \pm 13.0$ & $27 / 23$ & C19; E22; A9 & $26.2 \pm 2.2$ & $20 \mathrm{mg} / 2 \mathrm{~mL}, 500$ to $730 \mathrm{kDa}$ & \\
\hline Cerza et al, ${ }^{26}$ & PRP & $66.5 \pm 11.3$ & $25 / 35$ & E 2I/24/I5 & $\mathrm{N}$ & 4 times, $5.5 \mathrm{~mL}$, weekly & I, 2, 6 \\
\hline 2012 & $\mathrm{HA}$ & $66.2 \pm 10.6$ & $28 / 32$ & E $25 / 22 / 13$ & $\mathrm{~N}$ & 4 times, $20 \mathrm{mg} / 2 \mathrm{~mL}$ & \\
\hline Sanchez et al, ${ }^{20}$ & PRP & $60.5 \pm 7.9$ & $43 / 46$ & $E 45 / 32 / 12$ & $27.9 \pm 2.9$ & 3 times, $8 \mathrm{~mL}$, weekly & I, 2, 6 \\
\hline 2012 & $\mathrm{HA}$ & $58.9 \pm 8.2$ & $42 / 45$ & $\mathrm{E} 42 / 32 / 1 \mathrm{I}$ & $28.2 \pm 2.7$ & 3 times & \\
\hline Spakova et al, ${ }^{25}$ & PRP & $52.8 \pm 12.4$ & $33 / 27$ & E 2/39/19 & $27.9 \pm 4.1$ & 3 times, $3 \mathrm{~mL}$, weekly & 3,6 \\
\hline 2012 & $\mathrm{HA}$ & $53.2 \pm 14.5$ & $31 / 29$ & E 2/37/2I & $28.3 \pm 4.0$ & 3 times & \\
\hline Say et $\mathrm{al}^{24}$ & PRP & $55.2 \pm 7.8$ & $5 / 40$ & $\mathrm{E} \mathrm{I/I7/27}$ & $32.4 \pm 4.0$ & I time & 3,6 \\
\hline 2013 & LWHA & $56.2 \pm 5.1$ & $6 / 39$ & E I/I5/29 & $32.3 \pm 3.3$ & 3 times, $25 \mathrm{mg} / 2.5 \mathrm{~mL}, 730$ to $900 \mathrm{kDa}$, weekly & \\
\hline Vaquerizo et $\mathrm{al}^{27}$ & PRP & $62.4 \pm 6.6$ & $16 / 32$ & E 0/14/26; A8 & $30.7 \pm 3.6$ & 3 times, $8 \mathrm{~mL}$, every 2 weeks & 6,12 \\
\hline 2013 & HWHA & $64.8 \pm 7.7$ & $22 / 26$ & E 0/18/2I; A9 & $31.0 \pm 4.6$ & I time, $60 \mathrm{mg} / 3 \mathrm{~mL}$ & \\
\hline Filardo et al, ${ }^{28}$ & PRP & $53.3 \pm 13.2$ & $60 / 34$ & E $2.0 \pm 1.1$ & $26.6 \pm 4.0$ & 3 times, $5 \mathrm{~mL}$, weekly & $2,6,12$ \\
\hline 2015 & HWHA & $57.6 \pm 11.8$ & $52 / 37$ & E $2.0 \pm I . I$ & $26.9 \pm 4.4$ & 3 times, $20 \mathrm{mg} / 2 \mathrm{~mL},>1,500 \mathrm{kDa}$, weekly & \\
\hline Gormeli et al, ${ }^{29}$ & PRP* & $53.7 \pm 13.1$ & $23 / 16$ & E 26; AI3 & $28.7 \pm 4.8$ & 3 times, $5 \mathrm{~mL}$, weekly & 6 \\
\hline \multirow[t]{2}{*}{2017} & PRP \# & $53.8 \pm 13.4$ & $25 / 19$ & E 25; Al4 & $28.4 \pm 4.4$ & I time, $5 \mathrm{~mL}$ & \\
\hline & $\mathrm{HA}$ & $53.5 \pm 14$ & $22 / 17$ & E 27; AI3 & $29.7 \pm 3.7$ & 3 times, $20 \mathrm{mg} / 2 \mathrm{~mL}$, weekly & \\
\hline Raeissadat et al, ${ }^{30}$ & PRP & $56.9 \pm 9.1$ & $8 / 69$ & $\mathrm{E} 6 / 44 / 38 ; \mathrm{A} I 2$ & $28.2 \pm 4.6$ & 2 times, $5 \mathrm{~mL}$, monthly & $1,6,12$ \\
\hline 2015 & LWHA & $61.1 \pm 7.5$ & $15 / 47$ & $\mathrm{E} 0 / 47 / 37 ; \mathrm{A} 16$ & $27.0 \pm 4.2$ & 3 times, $20 \mathrm{mg} / 2 \mathrm{~mL}, 500$ to $730 \mathrm{kDa}$, monthly & \\
\hline Lana et $\mathrm{al},{ }^{31}$ & PRP & $60.9 \pm 7$ & $7 / 29$ & E 9/14/13 & $27.4 \pm 6.9$ & I time, $5 \mathrm{~mL}$ & $1,3,6,12$ \\
\hline \multirow[t]{2}{*}{2016} & HWHA & $60 \pm 6.6$ & $3 / 33$ & $E 9 / 16 / 11$ & $28.2 \pm 8.8$ & $20 \mathrm{mg} / 2 \mathrm{~mL}, 2,400$ to $3,600 \mathrm{kDa}$ & \\
\hline & P\&A & $62 \pm 6.1$ & $6 / 27$ & E 5/14/14 & $29.2 \pm 7.3$ & $5 \mathrm{~mL}+2 \mathrm{~mL}$ & \\
\hline Duymus et al, ${ }^{32}$ & PRP & $60.4 \pm 5.1$ & $1 / 32$ & $\mathrm{E} 0 / 22 / \mathrm{II}$ & $27.6 \pm 4.6$ & 2 times, $5 \mathrm{~mL}$ per time, every 2 weeks & $1,3,6,12$ \\
\hline 2017 & HWHA & $60.3 \pm 9.1$ & $1 / 33$ & $E 0 / 24 / 10$ & $28.4 \pm 3.6$ & $40 \mathrm{mg} / 2 \mathrm{~mL}, \mathrm{I}, 600 \mathrm{kDa}$ & \\
\hline Montanez-Heredia & PRP & $66.3 \pm 8.3$ & $12 / 15$ & $E 5 / 10 / 12$ & $29.0 \pm 5.5$ & 3 times, every 2 weeks & 3,6 \\
\hline et $\mathrm{al}^{33} 2016$ & LWHA & $61.5 \pm 8.6$ & $9 / 17$ & E 2/9/15 & $30.4 \pm 4.9$ & 3 times, $25 \mathrm{mg} / 2.5 \mathrm{~mL}, 799 \mathrm{kDa}$ & \\
\hline Cole et $\mathrm{al}^{21}$ & PRP & $55.9 \pm 10.4$ & $28 / 21$ & E $3 / 2620$ & $27.4 \pm 3.9$ & 3 times, $4 \mathrm{~mL}$, weekly & $3,6,12$ \\
\hline 2017 & LWHA & $56.8 \pm 10.5$ & $20 / 30$ & E I/27/22 & $29.0 \pm 6.4$ & 3 times, $16 \mathrm{mg} / 2 \mathrm{~mL}, 6,000 \mathrm{kDa}$ & \\
\hline
\end{tabular}

Notes: *Three injections of PRP; \#one injection of PRP. OA type (C/E/A): chondropathy, Kellgren grade 0/early, Kellgren grade I to III/advanced, Kellgren grade IV. Abbreviations: OA, osteoarthritis; BMI, body mass index; PRP, platelet-rich plasma; HA, hyaluronic acid; HWHA, high-molecular weight hyaluronic acid; LWHA, low-molecular weight hyaluronic acid; P\&A, PRP and HA.

However, different studies followed-up patients according to different protocols for baseline, 2 or 3, 6, and 12 months. Because of these data limitations, we can only evaluate the effects of the intervention at different times. Furthermore, we cocalculated the data from the second and third months after the intervention. Based on the available data pooled from six studies, there was no significant difference between these two groups when they were enrolled (MD $=0.88 ; 95 \% \mathrm{CI}:-3.45$ to $5.21 ; P=0.69 ; I^{2}=76 \%$ ). The PRP performed better than the HA after 3 months of treatment (MD=-10.82; 95\% CI: -19.74 to $-1.91 ; P=0.02 ; P^{2}=89 \%$ ). Taking time into consideration, this advantage continued at 6 months (MD $=-14.18 ; 95 \% \mathrm{CI}:-26.12$ to $-2.23 ; P=0.02$; $\left.I^{2}=95 \%\right)$ and 12 months (MD $=-15.25 ; 95 \% \mathrm{CI}:-22.17$ to $\left.-8.32 ; P<0.01 ; P^{2}=81 \%\right)$.

The WOMAC consists of three parts, including pain, stiffness, and physical function. For knee pain, the pooled data showed that patients treated with PRP had less pain than those treated with HA at 6 months (MD $=-2.0 ; 95 \% \mathrm{CI}:-3.60$ to $-0.39 ; P=0.01 ; I^{2}=90 \%$ ) and 12 months $(\mathrm{MD}=-2.22 ; 95 \%$ CI: -3.65 to $-0.79 ; P=0.002 ; P=92 \%)$. VAS was another parameter used to evaluate pain after treatment in four studies..$^{24,31-33}$ Two studies showed no significant difference between PRP and HA, while the others showed better pain reduction for PRP. Available data from Say et al and Duymus et al showed that PRP and HA performed similarly at 3 months (MD $=-0.98 ; 95 \% \mathrm{CI}:-2.55$ to $0.59 ; P=0.22$; $I^{2}=90 \%$ ) and 6 months (MD $=-0.82 ; 95 \% \mathrm{CI}:-1.80$ to 0.16 ; $\left.P=0.1 ; P^{2}=83 \%\right)$.

Physical function evaluated by the WOMAC was reported in four studies and showed that patients treated with PRP and HA had similar function recovery after 6 months of treatment (MD $=-5.78 ; 95 \% \mathrm{CI}:-14.73$ to $3.16 ; P=0.21 ; I^{2}=92 \%$ ). However, PRP performed better than HA at 12 months 


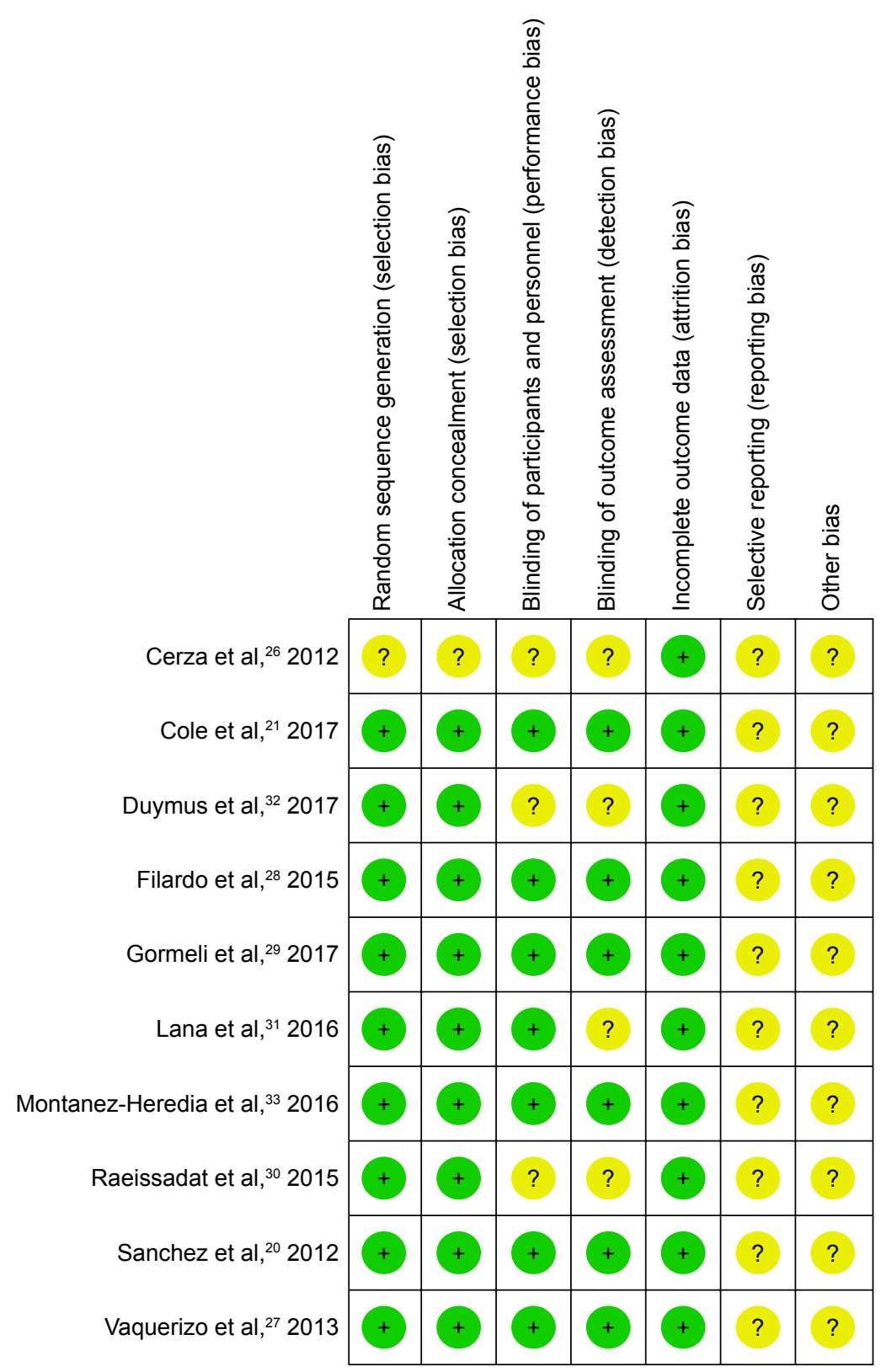

Figure 2 The summary of risk of bias of randomized controlled trials.

(MD $=-11.17 ; 95 \%$ CI: -16.37 to $-5.98 ; P<0.01 ; I^{2}=83 \%$ ). The EuroQol-visual analogue scales (EQ VAS) was also used to demonstrate functional recovery after treatment in four studies. ${ }^{912,28,29}$ The results showed that PRP and HA performed similarly at 6 months ( $\mathrm{MD}=2.19 ; 95 \% \mathrm{CI}:-11.47$ to 15.85 ; $P=0.75 ; I^{2}=98 \%$ ) and 12 months (MD $=-4.64 ; 95 \%$ CI: -21.79 to $\left.12.51 ; P=0.60 ; I^{2}=98 \%\right)$. In the study by Kon et al, ${ }^{9}$ high- and low-molecular weight H65As were compared to PRP, while one versus three injections of PRP were compared in a study by Gormeli et al. ${ }^{29}$ The use of high-molecular weight HA (HWHA) versus low-molecular weight HA (LWHA) or three injections versus one injection did not significantly influence the result.
The Subjective International Knee Documentation Committee (IKDC) was reported in several studies. ${ }^{9,21,28,29}$ Patients in the PRP group showed better IKDC scores than those in the HA group (MD=8.53; 95\% CI: 4.52 to 12.53 ; $\left.P<0.01 ; I^{2}=79 \%\right)$ at 6 months. The difference disappeared at 12 months (MD $=6.84 ; 95 \% \mathrm{CI}:-1.96$ to $15.63 ; P=0.13$; $\left.I^{2}=91 \%\right)$. These details are summarized in Table 3.

\section{Discussion}

$\mathrm{OA}$ in the knee, as a chronic progressive joint disease, is the second leading cause of loss of function; ${ }^{34}$ followed by a heavy economic and social burden. ${ }^{3}$ The etiology and pathogenesis 
Table 2 Quality assessment for nonrandomized trials

\begin{tabular}{|c|c|c|c|}
\hline $\begin{array}{l}\text { Quality assessment for } \\
\text { nonrandomized trials }\end{array}$ & $\begin{array}{l}\text { Kon } \\
\text { et al' }\end{array}$ & $\begin{array}{l}\text { Say } \\
\text { et } \mathbf{a l}^{24}\end{array}$ & $\begin{array}{l}\text { Spakova } \\
\text { et } \mathbf{a l}^{25}\end{array}$ \\
\hline A clearly stated aim & 2 & 2 & 2 \\
\hline Inclusion of consecutive patients & 2 & 0 & 0 \\
\hline Prospective data collection & 0 & 0 & 0 \\
\hline $\begin{array}{l}\text { Endpoints appropriate to the } \\
\text { aim of the study }\end{array}$ & 2 & 2 & 2 \\
\hline $\begin{array}{l}\text { Unbiased assessment of the } \\
\text { study endpoint }\end{array}$ & 0 & 0 & 0 \\
\hline $\begin{array}{l}\text { A follow-up period appropriate } \\
\text { to the aims of study }\end{array}$ & 2 & 2 & 2 \\
\hline Less than $5 \%$ loss to follow-up & 2 & 2 & 2 \\
\hline $\begin{array}{l}\text { Prospective calculation of the } \\
\text { sample size }\end{array}$ & 2 & 0 & 2 \\
\hline An adequate control group & 2 & 2 & 2 \\
\hline Contemporary groups & 2 & 2 & 2 \\
\hline Baseline equivalence of groups & 2 & 2 & 2 \\
\hline Adequate statistical analyses & 2 & 2 & 2 \\
\hline Total score & 20 & 16 & 18 \\
\hline
\end{tabular}

of knee osteoarthritis are still not clear, ${ }^{35}$ the main pathological change is the articular cartilage degeneration, with involved synovial fluid components changing as well. ${ }^{36}$ Hyaluronic acid synthesis is demolished and diluted by effusion, which made the molecular weight and concentration of endogenous HA decrease in the knee articular cavity of OA patients. ${ }^{37,38}$ All of the changes reduced the viscoelasticity of articular cartilage, and lowered the capability to resist mechanical stresses and damage.

As the most important component of synovial fluid, HA is an unbranched polyanionic polymer composed of $\mathrm{N}$-acetylD-glucosamine and D-glucosamine, which plays a role in nutrition and protection in the joints. ${ }^{40}$ The latest treatment guidelines for $\mathrm{OA}$ in the knee do not recommend HA as the main treatment; ${ }^{41}$ however, animal experiments have shown that HA plays a significant role in anti-inflammatory, anti-apoptotic, anti-angiogenic, and anti-fibrosis. ${ }^{42} \mathrm{~A}$ large number of clinical studies also demonstrated that HA has the effect of relieving joint pain and improving joint function. ${ }^{43-45}$ Some scholars demonstrated that HA treatment on severe knee osteoarthritis is not effective. The effectiveness of HA decreases after the multiple applications ${ }^{46,47}$ Furthermore, HA doesn't improve regeneration of damage cartilage particularly in the elder patients. ${ }^{48,49}$

PRP acts as a vector for large growth factors, ${ }^{12}$ which have the function of promoting tissue repair, ${ }^{50}$ which is increasingly being used in the treatment of OA. PRP maintains 4.6 times the platelet concentration compared to the original value. Some reports believe that PRP may induce precursor cells' migration, proliferation, and differentiation in the synovial fat pad or cartilage. Thereby, PRP could promote the repair of damaged cartilage, ${ }^{51,52}$ while reducing pain and the inflammatory response effect. ${ }^{53}$

For this study, the data based on three prospective and ten randomized trials showed no definitively better results for PRP than HA. Different results can be seen in the WOMAC, EQ VAS, VAS, IKDC, and other evaluation tools. Three prospective trials were included. Quality assessment scores ranged from 16 to 20 . No prospective calculation of the sample size was described in nonrandomized controlled trials. In addition, the assessment of the study endpoints was biased. All these shortcomings weaken the level of evidence.

There were insufficient data to conduct a subgroup analysis. Based on careful review of the included studies,

Table 3 Results of the meta-analysis

\begin{tabular}{|c|c|c|c|c|c|c|c|}
\hline Follow-up & Evaluation tools & Studies & Patients (PRP/HA) & MD & $95 \% \mathrm{Cl}$ & $P<0.05$ & $I^{2}$ \\
\hline \multirow[t]{4}{*}{3 months } & WOMAC total score & 3 & $153 / 154$ & -10.82 & -19.74 to -1.91 & Yes & $89 \%$ \\
\hline & WOMAC pain & 2 & $82 / 84$ & -0.5 & -1.66 to 0.66 & No & $81 \%$ \\
\hline & VAS & 2 & 78/79 & -0.98 & -2.55 to 0.59 & No & $95 \%$ \\
\hline & EQ VAS & 2 & $144 / 139$ & 5.91 & $-1.5 \mid$ to 13.34 & No & $79 \%$ \\
\hline \multirow[t]{6}{*}{6 months } & WOMAC total score & 5 & $290 / 289$ & -14.18 & -26.12 to -2.23 & Yes & $95 \%$ \\
\hline & WOMAC pain & 4 & $219 / 219$ & -2.0 & -3.60 to -0.39 & Yes & $90 \%$ \\
\hline & VAS & 2 & $78 / 79$ & -0.82 & -1.80 to 0.16 & No & $83 \%$ \\
\hline & WOMAC function & 3 & $170 / 169$ & -5.78 & -14.73 to 3.16 & No & $92 \%$ \\
\hline & EQ VAS & 4 & $232 / 228$ & 2.19 & -11.47 to 15.85 & No & $98 \%$ \\
\hline & IKDC & 4 & $232 / 228$ & 8.53 & 4.52 to 12.53 & Yes & $79 \%$ \\
\hline \multirow[t]{5}{*}{12 months } & WOMAC total score & 4 & $207 / 194$ & -15.25 & -22.17 to -8.32 & Yes & $81 \%$ \\
\hline & WOMAC pain & 3 & $158 / 144$ & -2.22 & -3.65 to -0.79 & Yes & $92 \%$ \\
\hline & WOMAC function & 3 & I58/I 44 & -11.17 & -16.37 to -5.98 & Yes & $83 \%$ \\
\hline & EQ VAS & 2 & $143 / 139$ & -4.64 & $-2 \mid .79$ to $|2.5|$ & No & $98 \%$ \\
\hline & IKDC & 2 & $143 / 139$ & 6.84 & -1.96 to 15.63 & No & $91 \%$ \\
\hline
\end{tabular}

Abbreviations: $\mathrm{Cl}$, confidence interval; EQ VAS, EuroQol-visual analog scales; HA, hyaluronic acid; IKDC, Subjective International Knee Documentation Committee; MD, mean difference; PRP, platelet-rich plasma; WOMAC, Western Ontario and McMaster Universities Osteoarthritis Index. 
we made a couple of observations. First, the components of PRP and HA were different among these studies. Although the PRP was produced from the patients' blood by a similar method of centrifugation, the platelet concentrations differed. Additionally, other products, such as cellular products and mediators, varied between the studies. HA was provided by several manufacturers with various molecular weights. Based on the description by Kon et $\mathrm{al}^{9}$ we defined LWHA as a molecular weight less than 1,000 kDa and HWHA as more than 1,000 kDa. HWHA was used in studies by Kon et al, ${ }^{9}$ Vaquerizo et al, ${ }^{27}$ Filardo et al, ${ }^{28}$ Lana et $a l,{ }^{31}$ and Duymus et al, ${ }^{32}$ while LWHA was used in studies by Kon et al, ${ }^{9}$ Say et al, ${ }^{24}$ Raeissadat et al, ${ }^{30}$ Montanez-Heredia et al, ${ }^{33}$ and Cole et al. ${ }^{21}$ The other studies did not provide detailed information about the HA molecular weight. ${ }^{20,25,26,29}$

The number of injections also varied among these studies, including a single injection, ${ }^{24,31}$ two injections ${ }^{30,32}$ or multiple injections. ${ }^{26}$ For the studies with multiple injections, the interval between the two injections was also different. The interval of 1 month was adopted in the study by Raeissadat et $\mathrm{al}^{30}$ and 2 weeks was used by Kon et al, ${ }^{9}$ Vaquerizo et $\mathrm{al}^{27}$ Duymus et $\mathrm{al},{ }^{32}$ and Montanez-Heredia et al. ${ }^{33}$ In a prospective, randomized trial, Gormeli et al compared HA with multiple- or single-dose PRP. ${ }^{29}$ There were no differences between HA and single-dose PRP, while multiple-dose PRP was better than both treatments.

The pathology of knee OA changes from chondropathy without appearance on X-ray. Patients at different stages do not have the same response to the same treatment. Filardo et al concluded that PRP was more effective in young patients with early or moderate stages of arthrosis, but it had a limited effect in cases of advanced OA. ${ }^{54}$ Chang et al evaluated the effects of intra-articular injection of PRP or HA in a systematic review and reported better results among those patients with milder forms of OA than advanced forms. ${ }^{55}$ Most patients in our analysis suffered from early stage knee OA, ranging from grades 1 to 3 , for a total of 1,390 participants $(91.2 \%)$. There were 72 grade 4 knee OA patients enrolled in three studies, ${ }^{9,27,30}$ which may have altered the treatment effect.

Additionally, previous studies showed that the efficacy of intra-articular injection of HA or PRP depended on time. Filardo et al reported improvement after 2 months of treatment, which was confirmed at 6 months of follow-up, and there was a tendency to worsen after 6 to 12 months. ${ }^{56}$ Similar results were reported in another study in which the positive therapeutic efficacy of HA peaked at 8 weeks and lasted for up to 6 months. ${ }^{47}$ This tendency may influence the calculation and analysis in our studies because different test points were used, and we combined data from 2 and 3 months.

Beyond those differences in the study intervention, the mechanism of PRP and HA in the change in knee OA was another important factor that influenced the treatment effects. The beneficial effects of HA may be attributable to improved lubrication based on the viscoelasticity and/or the improvement of the intra-articular environment by rebuilding the barrier between the synovial membrane and the articular surface. ${ }^{57}$ The growth factors secreted from active platelets have a fundamental function to stimulate proliferation and differentiation of chondrocytes, regulate collagenase secretion, and regenerate cartilage. ${ }^{58} \mathrm{HA}$ acts as a lubricator, while PRP provides many factors to stimulate the synovial membrane and surrounding tissues. The combination of HA and PRP may be more effective than either alone, as Lana et al concluded (the combination of HA and PRP resulted in better outcomes than HA alone at up to 1 year and PRP alone at up to 3 months). ${ }^{31}$

Our current study included the most recent trials comparing HA and PRP, though we must acknowledge the limitations of the analysis. The first and serious limitation was that there was significant heterogeneity in each calculation. Second, too many evaluation tools were used across the different studies such that the highest number of studies that used any single evaluation tool was five studies for the WOMAC score at 6 months. A funnel plot could not be drawn to analyze the publication bias. These limitations weakened our ability to draw a definitive study conclusion.

\section{Conclusion}

PRP injections reduced pain more effectively than HA injections in OA of the knee at 6 and 12 months of follow-up evaluated by WOMAC pain score, while the VAS showed no significant difference at 3 and 6 months. Additionally, similar results were observed for the function recovery according to the WOMAC function score and EQ VAS. Due to the limited quality and data of the evidence currently available, more high-quality randomized controlled trials are required.

\section{Acknowledgment}

This work was supported by funding from the National Natural Science Foundation of China (number 81501887).

\section{Disclosure}

The authors report no conflicts of interest in this work. 


\section{References}

1. Wearing SC, Hennig EM, Byrne NM, Steele JR, Hills AP. Musculoskeletal disorders associated with obesity: a biomechanical perspective. Obes Rev. 2006;7(3):239-250.

2. Busija L, Bridgett L, Williams SR, Osborne RH, Buchbinder R, March L, Fransen M. Osteoarthritis. Best Pract Res Clin Rheumatol. 2010;24(6):757-768.

3. Stewart WF, Ricci JA, Chee E, Morganstein D, Lipton R. Lost productive time and cost due to common pain conditions in the US workforce. JAMA. 2003;290(18):2443-2454.

4. Bijlsma JW, Berenbaum F, Lafeber FP. Osteoarthritis: an update with relevance for clinical practice. Lancet. 2011;377(9783):2115-2126.

5. No authors listed. From the Centers for Disease Control and Prevention. Prevalence of disabilities and associated health conditions among adults - United States, 1999. JAMA. 2001;285(12):1571-1572.

6. Zhang W, Moskowitz RW, Nuki G, et al. OARSI recommendations for the management of hip and knee osteoarthritis, Part II: OARSI evidence-based, expert consensus guidelines. Osteoarthritis Cartilage. 2008;16(2):137-162.

7. Juni P, Reichenbach S, Trelle S, et al. Efficacy and safety of intraarticular hylan or hyaluronic acids for osteoarthritis of the knee: a randomized controlled trial. Arthritis Rheum. 2007;56(11):3610-3619.

8. Bellamy N, Campbell J, Robinson V, Gee T, Bourne R, Wells G. Viscosupplementation for the treatment of osteoarthritis of the knee. Cochrane Database Syst Rev. 2005(2):CD005321.

9. Kon E, Mandelbaum B, Buda R, et al. Platelet-rich plasma intra-articular injection versus hyaluronic acid viscosupplementation as treatments for cartilage pathology: from early degeneration to osteoarthritis. Arthroscopy. 2011;27(11):1490-1501.

10. Gobbi A, Bathan L. Biological approaches for cartilage repair. J Knee Surg. 2009;22(1):36-44.

11. Grimaud E, Heymann D, Redini F. Recent advances in TGF-beta effects on chondrocyte metabolism. Potential therapeutic roles of TGFbeta in cartilage disorders. Cytokine Growth Factor Rev. 2002;13(3): 241-257.

12. Cole BJ, Seroyer ST, Filardo G, Bajaj S, Fortier LA. Platelet-rich plasma: where are we now and where are we going? Sports Health. 2010;2(3):203-210.

13. Anitua E, Andia I, Ardanza B, Nurden P, Nurden AT. Autologous platelets as a source of proteins for healing and tissue regeneration. Thromb Haemost. 2004;91(1):4-15.

14. Marx RE. Platelet-rich plasma: evidence to support its use. J Oral Maxillofac Surg. 2004;62(4):489-496.

15. Foster TE, Puskas BL, Mandelbaum BR, Gerhardt MB, Rodeo SA. Platelet-rich plasma: from basic science to clinical applications. Am J Sports Med. 2009;37(11):2259-2272.

16. Senet P, Bon FX, Benbunan M, et al. Randomized trial and local biological effect of autologous platelets used as adjuvant therapy for chronic venous leg ulcers. J Vasc Surg. 2003;38(6):1342-1348.

17. Kon E, Filardo G, Di Martino A, Marcacci M. Platelet-rich plasma (PRP) to treat sports injuries: evidence to support its use. Knee Surg Sports Traumatol Arthrosc. 2011;19(4):516-527.

18. Laudy AB, Bakker EW, Rekers M, Moen MH. Efficacy of platelet-rich plasma injections in osteoarthritis of the knee: a systematic review and meta-analysis. Br J Sports Med. 2015;49(10):657-672.

19. Liu J, Song W, Yuan T, Xu Z, Jia W, Zhang C. A comparison between platelet-rich plasma (PRP) and hyaluronate acid on the healing of cartilage defects. PLoS One. 2014;9(5):e97293.

20. Sanchez M, Fiz N, Azofra J, et al. A randomized clinical trial evaluating plasma rich in growth factors (PRGF-Endoret) versus hyaluronic acid in the short-term treatment of symptomatic knee osteoarthritis. Arthroscopy. 2012;28(8):1070-1078.

21. Cole BJ, Karas V, Hussey K, Pilz K, Fortier LA. Hyaluronic acid versus platelet-rich plasma: a prospective, double-blind randomized controlled trial comparing clinical outcomes and effects on intra-articular biology for the treatment of knee osteoarthritis. Am J Sports Med. 2017;45(2):339-346.
22. Sadabad HN, Behzadifar M, Arasteh F, Dehghan HR. Efficacy of platelet-rich plasma versus hyaluronic acid for treatment of knee osteoarthritis: a systematic review and meta-analysis. Electron Physician. 2016;8(3):2115-2122.

23. Sanchez M, Anitua E, Azofra J, Aguirre JJ, Andia I. Intra-articular injection of an autologous preparation rich in growth factors for the treatment of knee OA: a retrospective cohort study. Clin Exp Rheumatol. 2008;26(5):910-913.

24. Say F, Gurler D, Yener K, Bulbul M, Malkoc M. Platelet-rich plasma injection is more effective than hyaluronic acid in the treatment of knee osteoarthritis. Acta Chir Orthop Traumatol Cech. 2013;80(4): 278-283.

25. Spakova T, Rosocha J, Lacko M, Harvanova D, Gharaibeh A. Treatment of knee joint osteoarthritis with autologous platelet-rich plasma in comparison with hyaluronic acid. Am J Phys Med Rehabil. 2012; 91(5):411-417.

26. Cerza F, Carni S, Carcangiu A, et al. Comparison between hyaluronic acid and platelet-rich plasma, intra-articular infiltration in the treatment of gonarthrosis. Am J Sports Med. 2012;40(12):2822-2827.

27. Vaquerizo V, Plasencia MA, Arribas I, Seijas R, Padilla S, Orive G, Anitua E. Comparison of intra-articular injections of plasma rich in growth factors (PRGF-Endoret) versus Durolane hyaluronic acid in the treatment of patients with symptomatic osteoarthritis: a randomized controlled trial. Arthroscopy. 2013;29(10):1635-1643.

28. Filardo G, Di Matteo B, Di Martino A, et al. Platelet-rich plasma intra-articular knee injections show no superiority versus viscosupplementation: a randomized controlled trial. Am J Sports Med. 2015;43(7): 1575-1582.

29. Gormeli G, Gormeli CA, Ataoglu B, Colak C, Aslanturk O, Ertem K. Multiple PRP injections are more effective than single injections and hyaluronic acid in knees with early osteoarthritis: a randomized, doubleblind, placebo-controlled trial. Knee Surg Sports Traumatol Arthrosc. 2017;25(3):958-965.

30. Raeissadat SA, Rayegani SM, Hassanabadi Fathi M, Ghorbani E, Babaee M, Azma K. Knee osteoarthritis injection choices: plateletrich plasma (PRP) versus hyaluronic acid (a one-year randomized clinical trial). Clin Med Insights Arthritis Musculoskelet Disord. 2015; 8:1-8.

31. Lana JF, Weglein A, Sampson SE, et al. Randomized controlled trial comparing hyaluronic acid, platelet-rich plasma and the combination of both in the treatment of mild and moderate osteoarthritis of the knee. J Stem Cells Regen Med. 2016;12(2):69-78.

32. Duymus TM, Mutlu S, Dernek B, Komur B, Aydogmus S, Kesiktas FN. Choice of intra-articular injection in treatment of knee osteoarthritis: platelet-rich plasma, hyaluronic acid or ozone options. Knee Surg Sports Traumatol Arthrosc. 2017;25(2):485-492.

33. Montanez-Heredia E, Irizar S, Huertas PJ, et al. Intra-articular injections of platelet-rich plasma versus hyaluronic acid in the treatment of osteoarthritic knee pain: a randomized clinical trial in the context of the Spanish National Health Care system. Int J Mol Sci. 2016;17(7): E1064.

34. Lawrence RC, Felson DT, Helmick CG, et al. Estimates of the prevalence of arthritis and other rheumatic conditions in the United States. Part II. Arthritis Rheum. 2008;58(1):26-35.

35. Gobbi A, Lad D, Karnatzikos G. The effects of repeated intra-articular PRP injections on clinical outcomes of early osteoarthritis of the knee. Knee Surg Sports Traumatol Arthrosc. 2015;23(8):2170-2177.

36. Aigner T, Kim HA. Apoptosis and cellular vitality: issues in osteoarthritic cartilage degeneration. Arthritis Rheum. 2002;46(8):1986-1996.

37. Myint P, Deeble DJ, Beaumont PC, Blake SM, Phillips GO. The reactivity of various free radicals with hyaluronic acid: steady-state and pulse radiolysis studies. Biochim Biophys Acta. 1987;925(2):194-202.

38. Ono Y, Sakai T, Hiraiwa H, et al. Chondrogenic capacity and alterations in hyaluronan synthesis of cultured human osteoarthritic chondrocytes. Biochem Biophys Res Commun. 2013;435(4):733-739.

39. Campo GM, Avenoso A, D'Ascola A, et al. 4-Mer hyaluronan oligosaccharides stimulate inflammation response in synovial fibroblasts in part via TAK-1 and in part via p38-MAPK. Curr Med Chem. 2013; 20(9):1162-1172. 
40. Reitinger S, Lepperdinger G. Hyaluronan, a ready choice to fuel regeneration: a mini-review. Gerontology. 2013;59(1):71-76.

41. Jevsevar DS, Brown GA, Jones DL, et al. The American Academy of Orthopaedic Surgeons evidence-based guideline on: treatment of osteoarthritis of the knee, 2nd edition. J Bone Joint Surg Am. 2013;95(20): 1885-1886.

42. Abate M, Pulcini D, Di Iorio A, Schiavone C. Viscosupplementation with intra-articular hyaluronic acid for treatment of osteoarthritis in the elderly. Curr Pharm Des. 2010;16(6):631-640.

43. Hunter DJ, Lo GH. The management of osteoarthritis: an overview and call to appropriate conservative treatment. Rheum Dis Clin North Am. 2008;34(3):689-712.

44. Campbell J, Bellamy N, Gee T. Differences between systematic reviews/ meta-analyses of hyaluronic acid/hyaluronan/hylan in osteoarthritis of the knee. Osteoarthritis Cartilage. 2007;15(12):1424-1436.

45. Miller LE, Block JE. US-approved intra-articular hyaluronic acid injections are safe and effective in patients with knee osteoarthritis: systematic review and meta-analysis of randomized, saline-controlled trials. Clin Med Insights Arthritis Musculoskelet Disord. 2013;6:57-63.

46. Dagenais S. Intra-articular hyaluronic acid (viscosupplementation) for knee osteoarthritis. Issues Emerg Health Technol. 2006;(94):1-4.

47. Bannuru RR, Natov NS, Dasi UR, Schmid CH, McAlindon TE. Therapeutic trajectory following intra-articular hyaluronic acid injection in knee osteoarthritis - meta-analysis. Osteoarthritis Cartilage. 2011;19(6): 611-619.

48. Ucar D, Diracoglu D, Suleyman T, Capan N. Intra-articular hyaluronic acid as treatment in elderly and middle-aged patients with knee osteoarthritis. Open Rheumatol J. 2013;7:38-41.

49. Andia I, Abate M. Knee osteoarthritis: hyaluronic acid, platelet-rich plasma or both in association? Expert Opin Biol Ther. 2014;14(5): $635-649$.
50. Patel S, Dhillon MS, Aggarwal S, Marwaha N, Jain A. Treatment with platelet-rich plasma is more effective than placebo for knee osteoarthritis: a prospective, double-blind, randomized trial. Am J Sports Med. 2013;41(2):356-364.

51. Karystinou A, Dell'Accio F, Kurth TB, et al. Distinct mesenchymal progenitor cell subsets in the adult human synovium. Rheumatology (Oxford). 2009;48(9):1057-1064.

52. Manferdini C, Maumus M, Gabusi E, et al. Adipose-derived mesenchymal stem cells exert antiinflammatory effects on chondrocytes and synoviocytes from osteoarthritis patients through prostaglandin E2. Arthritis Rheum. 2013;65(5):1271-1281.

53. de Vries-van Melle ML, Narcisi R, Kops N, et al. Chondrogenesis of mesenchymal stem cells in an osteochondral environment is mediated by the subchondral bone. Tissue Eng Part A. 2014;20(1-2):23-33.

54. Filardo G, Kon E, Roffi A, Di Matteo B, Merli ML, Marcacci M. Platelet-rich plasma: why intra-articular? A systematic review of preclinical studies and clinical evidence on PRP for joint degeneration. Knee Surg Sports Traumatol Arthrosc. 2015;23(9):2459-2474.

55. Chang KV, Hung CY, Aliwarga F, Wang TG, Han DS, Chen WS Comparative effectiveness of platelet-rich plasma injections for treating knee joint cartilage degenerative pathology: a systematic review and meta-analysis. Arch Phys Med Rehabil. 2014;95(3):562-575.

56. Filardo G, Kon E, Buda R, et al. Platelet-rich plasma intra-articular knee injections for the treatment of degenerative cartilage lesions and osteoarthritis. Knee Surg Sports Traumatol Arthrosc. 2011;19(4):528-535.

57. Namiki O, Toyoshima $\mathrm{H}$, Morisaki N. Therapeutic effect of intra-articular injection of high molecular weight hyaluronic acid on osteoarthritis of the knee. Int J Clin Pharmacol Ther Toxicol. 1982;20(11):501-507.

58. Leitner GC, Gruber R, Neumuller J, et al. Platelet content and growth factor release in platelet-rich plasma: a comparison of four different systems. Vox Sang. 2006;91(2):135-139.

\section{Publish your work in this journal}

Drug Design, Development and Therapy is an international, peerreviewed open-access journal that spans the spectrum of drug design and development through to clinical applications. Clinical outcomes, patient safety, and programs for the development and effective, safe, and sustained use of medicines are the features of the journal, which

\section{Dovepress}

has also been accepted for indexing on PubMed Central. The manuscript management system is completely online and includes a very quick and fair peer-review system, which is all easy to use. Visit http://www.dovepress.com/testimonials.php to read real quotes from published authors. 